\title{
APROVEITAMENTO DE RESÍDUOS DE CONSTRUÇÃO E DEMOLIÇÃO COM FOCO NA SUSTENTABILIDADE ${ }^{1}$
}

\author{
USE OF CONSTRUCTION AND DEMOLITION \\ WASTE WITH A FOCUS ON SUSTAINABILITY
}

\section{Roberta Cristina Casarotto Mezech ${ }^{2}$ e Ana Paula Meneghetti de Freitas ${ }^{3}$}

\section{RESUMO}

O presente artigo, de natureza eminentemente teórica, é resultado de uma pesquisa do Curso de Pós-Graduação em Gerenciamento da Construção Civil da Universidade Franciscana. O desenvolvimento social e econômico da humanidade proporcionou um expressivo aumento da exploração dos recursos naturais e, consequentemente, uma crescente preocupação com a degradação ao meio ambiente. A construção civil contribui significativamente com a geração de resíduos que, se descartados indevidamente, acabam causando consideráveis impactos ambientais. O reaproveitamento dos materiais utilizados na obra proporciona benefícios, tanto ambientais quanto econômicos e sociais, resultando em economia na aquisição de matéria-prima, como também, preservando as reservas naturais e diminuindo a poluição causada pelos resíduos. Este artigo tem como objetivo mostrar o aproveitamento de resíduos de construção e demolição, com foco na sustentabilidade. Entre os benefícios gerados pelo aproveitamento de resíduos está o atendimento a Objetivos de Desenvolvimento Sustentável das Nações Unidas (ODS). O artigo denota expressiva importância para as empresas de construção civil, pois oferece uma contribuição, por meio das análises bibliográficas, auxiliando na tomada de decisão e melhorias futuras. Para elaboração deste artigo foi realizada uma pesquisa bibliográfica por meio da revisão de literatura, análise crítica e seleção. Nos estudos verificou-se a realização de diversas ações para o aproveitamento de Resíduos de Construção e Demolição (RCD), favorecendo o atendimento do Objetivo de Desenvolvimento Sustentável 12: consumo e produção responsáveis.

Palavras-chave: Impactos Ambientais, Reaproveitamento, Desenvolvimento Sustentável.

\section{ABSTRACT}

The present article, of an eminently theoretical nature, it is the result of research on the Postgraduate Course in Construction Management at the Universidade Franciscana. The social and economic development of humanity has provided a significant increase in the exploitation of natural resources and, consequently, an increasing concern with the degradation to the environment. Civil construction contributes significantly to the generation of waste that, if improperly disposed of, ends up causing considerable environmental impacts. The reuse of the materials used in the work provides benefits, both environmental, economic and social, resulting in savings in the acquisition of raw materials, as well as preserving natural reserves and reducing pollution caused by waste. This article aims to show the use of construction and demolition waste, with a focus on sustainability. Among the benefits generated by the use of waste is the fulfillment of the United Nations Sustainable Development Goals (SDGs). This article shows significant importance for civil construction companies, as it offers a contribution, through bibliographic analyzes of the benefits of using construction and demolition waste and suggestion to meet the sustainable objectives of the UN, assisting in decision making 1 Trabalho de Iniciação Científica.

2 Acadêmica do Curso de Pós-graduação em Gerenciamento na Construção Civil - Universidade Franciscana. E-mail: robertamezech@hotmail.com.

3 Orientadora Ana Paula Meneghetti de Freitas - Universidade Franciscana. E-mail: anameneghetti@gmail.com 
and improvements future. To this end, a bibliographic search was carried out, based on the deductive method. In the studies, several actions were verified for the use of construction and demolition waste, favoring the achievement of Sustainable Development Goal 12: responsible consumption and production.

Keywords: Environmental Impacts, Reuse, Sustainable Development.

\section{INTRODUÇ̃̃O}

A indústria da construção civil apresenta características, tais como: elevado desperdício e grande impacto ambiental ocasionado em termos de volume de resíduos gerados e matéria-prima consumida. Grande parte dos profissionais da construção civil ignora a quantidade de resíduos sólidos gerados a partir da demolição e construção de obras civis e, quando conscientes da poluição ambiental, não estão orientados de como fazer uma destinação seletiva dos resíduos, através de uma deposição correta e de uma triagem, separando os resíduos passíveis de reciclagem e/ou reutilização. A prática da reciclagem dos resíduos oriundos da construção civil é de suma importante para a sustentabilidade da nossa sociedade, porque ela está diretamente relacionada com atenuação do impacto ambiental gerado pelo setor e redução de custos de gerenciamento do resíduo. Estima-se que o setor é responsável por consumir cerca de $20 \%$ a $50 \%$ do total de recursos naturais utilizados pela sociedade. (MARINHO, 2019, p. 26).

Os resíduos da construção civil são todos os resíduos provenientes de construções, reformas, reparos e demolições de obras de construção civil. Além dos resultantes da preparação e da escavação de terrenos, como: tijolos, blocos cerâmicos, concreto em geral, solos, rochas, metais, resinas, colas, tintas, madeiras e compensados, forros, argamassa, gesso, telhas, pavimento asfáltico, vidros, plásticos, tubulações, fiação elétrica etc., os quais são comumente chamados de entulhos de obras (BRASIL, 2002).

O desenvolvimento social e econômico da humanidade afeta significativamente o meio ambiente, provocando impactos ambientais. A indústria da construção civil é responsável por um consumo de materiais considerável, colaborando de forma expressiva nos impactos ambientais, desde a sua extração da matéria-prima, produção de materiais, execução da obra e demolição, gerando grande quantidade de entulhos. Os resíduos da construção civil, muitas vezes, são indevidamente descartados, trazendo consequências muito nocivas ao meio ambiente.

Com a crescente degradação do meio ambiente, a sustentabilidade entra como alternativa para minimizar os impactos, visando garantir um mundo melhor para as futuras gerações. Por exemplo, a reciclagem dos entulhos gerados em obras é uma das formas de conservação dos recursos naturais extraídos pelo setor da construção civil e redução dos impactos ambientais por eles gerados.

A temática escolhida aborda o aproveitamento de resíduos de construção e demolição (RCD) gerados na obra, extremamente prejudiciais ao meio ambiente, visando à busca pelo equilíbrio entre a 
produção e a preservação ambiental, com foco na sustentabilidade. Conceitua-se sustentabilidade como ações para que os recursos naturais sejam suficientes para todos, incluindo as gerações futuras e, ao mesmo tempo, que promovam a redução dos danos causados por esses resíduos à natureza (ONU, 2020).

Outro benefício do aproveitamento de resíduos de construção e demolição consiste no atendimento aos 7 R's da sustentabilidade: reduza, repense, responsabilize-se, reintegre, recuse, reaproveite e recicle (AUTOSSUSTENTÁVEL, 2017). Segundo Essolar (2018), o objetivo dos 7 R's da sustentabilidade é: "a criação de soluções ambientais, já que a sociedade se mostrava altamente consumidora, produtora de grande quantidade de lixo e não fazia a destinação correta dos resíduos".

De acordo com Marinho (2019) as questões fundamentais que precisam ser consideradas em qualquer discussão relacionada ao desenvolvimento sustentável são: o bem-estar humano, o meio ambiente e o futuro. Desse modo, temas como poluição, biodiversidade, exploração de recursos naturais, efeitos climáticos, entre outros, devem ser relacionados a desemprego, pobreza e riqueza, tecnologias, valores culturais e organizações políticas e sociais.

Sendo assim, o artigo auxilia de forma positiva as empresas de construção civil, pois oferece uma contribuição, por meio de bibliografias relevantes acerca do aproveitamento dos resíduos e sugestão ao atendimento dos objetivos sustentáveis da ONU, auxiliando na tomada de decisão e melhorias futuras.

Este artigo tem como objetivo mostrar o aproveitamento de resíduos de construção e demolição, com foco em sustentabilidade. Entre os benefícios gerados pelo aproveitamento de resíduos está o atendimento aos Objetivos de Desenvolvimento Sustentável das Nações Unidas (ODS), como o Objetivo de Desenvolvimento Sustentável 12: consumo e produção responsáveis que busca assegurar padrões de produção e de consumo sustentáveis, visando até 2030, alcançar a gestão sustentável e o uso eficiente dos recursos naturais e, até 2030, reduzir substancialmente a geração de resíduos por meio da prevenção, redução, reciclagem e reuso (ONU, 2020). As empresas de construção podem buscar o atendimento desse objetivo por meio de uma gestão de resíduos na obra.

\section{MATERIAL E MÉTODOS}

Para elaboração deste artigo foi realizada uma pesquisa bibliográfica por meio da revisão de literatura, análise crítica e seleção. O método de abordagem é o dedutivo. Com a finalidade de, inicialmente, reconhecer o campo de pesquisas e investigar as produções, por meio do mapeamento de trabalhos já publicados, foram selecionadas produções no banco de dados do Portal brasileiro de publicações científicas em acesso aberto (OASISBR), do Instituto Brasileiro de Informação em Ciências e Tecnologia (IBICT), referendado por OASIS/IBICT; na RESEARCHGATE, rede social de cientistas e na GOOGLE SCHOLAR, plataforma de pesquisa da empresa Google.

Para a realização do mapeamento no banco de dados, foram utilizados os seguintes descritores/palavras-chave: "resíduos de construção e demolição", "reutilização", "reciclagem", 
"sustentabilidade em canteiro de obras" e "desenvolvimento sustentável". Os trabalhos encontrados passaram por uma seleção. Os seguintes parâmetros foram considerados: ano da publicação e relevância do tema para a sustentabilidade.

Após a seleção, os trabalhos passaram por uma análise crítica, onde buscamos identificar: objetivos e os principais resultados alcançados. A partir dessa análise realizou-se uma nova seleção nos trabalhos que, separados, foram estudados mais profundamente.

Em seguida, foram pesquisados os descritores "resíduos", "reutilização" e "reciclagem", na Resolução 307/2002 do Conselho Nacional do Meio Ambiente (CONAMA), encontrando na mesma a classificação dos resíduos em classes e sua destinação. A NBR 10.004/2004 também foi de extrema importância na classificação dos mesmos. Ademais, foram pesquisados os Objetivos de Desenvolvimento Sustentável e os 7 R's da sustentabilidade, ambos de importante relevância para o tema.

\section{RESULTADOS E DISCUSSÃO}

\section{SUSTENTABILIDADE E RESÍDUOS DE CONSTRUÇÃO E DEMOLIÇÃO}

A sustentabilidade na construção civil vem conquistando cada vez mais importância, a qual visa garantir a redução de impactos ambientais, sendo feitas ações que assegurem o melhor para o meio ambiente, potencializando a viabilidade econômica e garantindo uma boa qualidade de vida para as atuais e futuras gerações. Com essa preocupação, surgiram os 7 R's com o objetivo de conscientizar a população e diminuir os impactos gerados ao meio ambiente, tendo um consumo mais consciente. Os 7 R's consistem em: repensar, reduzir, responsabilizar-se, reintegrar, recusar, reaproveitar e reciclar. (IDEC, 2019).

Inclusive, sobre essa temática, a Assembleia Geral das Nações Unidas estabeleceu Objetivos de Desenvolvimento Sustentável, que consiste em 17 objetivos globais para acabar com a pobreza, proteger o meio ambiente e o clima e garantir paz e prosperidade a todas a pessoas (ONU, 2020). Entre os objetivos está o Objetivo de Desenvolvimento Sustentável 12: consumo e produção responsáveis. Esse objetivo busca assegurar padrões de produção e de consumo sustentáveis, visando até 2030, alcançar a gestão sustentável e o uso eficiente dos recursos naturais e, até 2030, reduzir substancialmente a geração de resíduos por meio da prevenção, redução, reciclagem e reuso (ONU, 2020).

Práticas de reutilização de resíduos podem trazer diversos benefícios socioambientais, culturais e econômicos, seja por processos de inclusão social, educação ambiental, ou pela diminuição de custos com a produção, extração de recursos naturais, energia, minimização de impactos ambientais" (ROQUE et al., 2020, p. 742).

"As atividades de construção geram 40\% de todos os resíduos gerados pela sociedade" (TELLO; RIBEIRO, 2012, p. 24). Resíduos de construção e demolição "são os provenientes de construções, 
reformas, reparos e demolições de obras de construção civil, e os resultantes da preparação e da escavação de terrenos (...)" (BRASIL, 2002, p. 571). As reformas, ampliações e demolições têm participação de $59 \%$ na geração de resíduos, enquanto as novas construções geram 41\%, como mostra a Figura 1.

Figura 1 - Origem dos resíduos de construção em algumas cidades brasileiras.

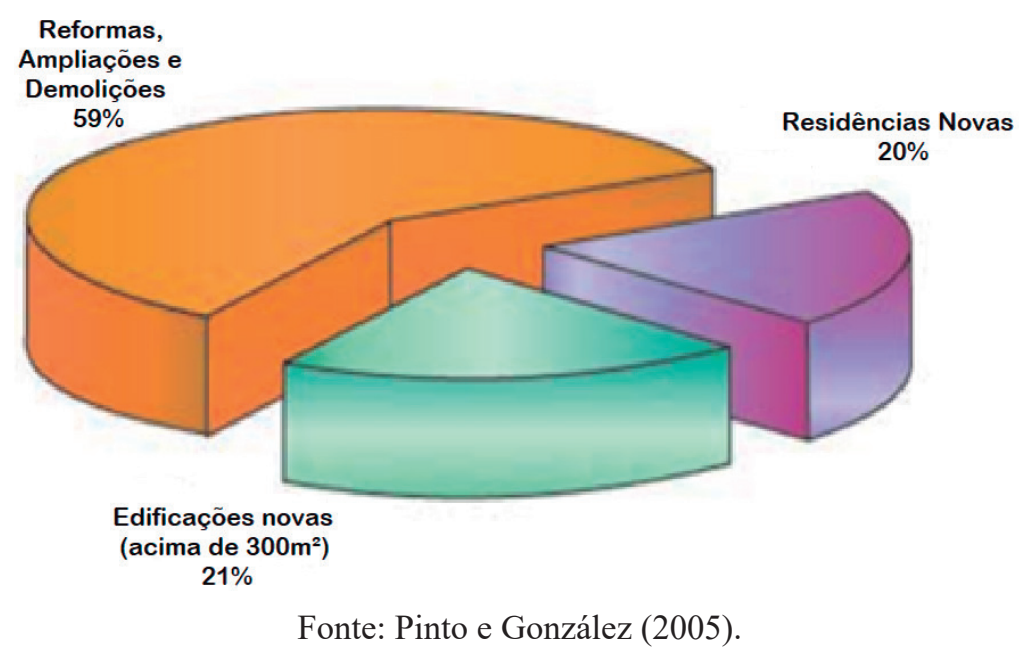

Esses resíduos, muitas vezes, são descartados indevidamente, causando problemas ao entorno. Como afirma Costa et al. (2006, p. 446), “(...) este tipo de resíduo tem recebido grande atenção por parte de prefeituras e de órgãos responsáveis devido aos problemas causados pela sua deposição indevida, pois aquelas têm que arcar com os custos de sua remoção quando os infratores não são identificados".

“Gasta-se em torno de R \$ 2 milhões/mensais com recolhimento de entulho disposto clandestinamente em centros urbanos acima de dois milhões de habitantes. Pode-se dizer que $50 \%$ do entulho é disposto irregularmente na maioria dos centros urbanos brasileiros de médio e grande porte" (BLUMENSCHEIN, 2007, p. 2).

"A fase em que se observa a maior quantidade de desperdício de materiais é na de execução da obra, ou seja, no canteiro de obra, que é onde a perda representa a diferença entre a quantidade prevista no projeto e a quantidade efetivamente consumida" (ALBUQUERQUE; SANTANA, 2018, p. 3). A quantidade de materiais desperdiçados em três obras é possível a construção de uma quarta, idêntica (PERINA; TRANNIN, 2019, p. 2).

Segundo Albuquerque e Santana (2018, p. 4), “uma grande parte dos resíduos provenientes de canteiros de obras é depositada clandestinamente em terrenos baldios, várzeas e taludes de cursos d'água, o que gera impactos ambientais visíveis (...)”. Outra forma de descarte de resíduos é a deposição a céu aberto, na qual é feita a queima dos resíduos no canteiro de obras, causando grande poluição atmosférica (ALBUQUERQUE; SANTANA, 2018, p. 5). Outro impacto negativo ao meio ambiente, segundo Fernandes e Filho (2016, p. 3), é que os resíduos quando não reaproveitados exige a retirada de matéria prima não renovável, devastando recursos naturais. 
"A gestão e logística de materiais e recursos dentro do canteiro de obras são de suma importância, uma vez que lidam com a disposição adequada dos materiais que serão utilizados durante toda a fase de execução. Não menos importante é a deposição adequada dos resíduos e seu reuso no próprio canteiro. No canteiro, são gerados vários tipos de resíduos além do resíduo da construção, normalmente conhecido como entulho. " (ZEULE, 2017, p. 62).

A Resolução 307/2002 do Conselho Nacional do Meio Ambiente (CONAMA) buscou atender a essa problemática, como afirma Fernandes e Filho:

Buscando atender a essa problemática a Resolução 307/2002 do Conselho Nacional do Meio Ambiente - CONAMA, endossa a Agenda 21 (1992), segundo a qual reduzir, reutilizar e reciclar constituem hierarquicamente as ações necessárias para o manejo ambientalmente saudável dos resíduos e explicita no Art. $2^{\circ}$, parágrafo V que o gerenciamento de resíduos: "é o sistema de gestão que visa reduzir, reutilizar ou reciclar resíduos, incluindo planejamento, responsabilidades, práticas, procedimentos e recursos para desenvolver e implementar as ações necessárias ao cumprimento das etapas previstas em programas e planos" (FERNANDES; FILHO, 2016, p. 3).

Segundo Monteiro (2019) as questões relativas ao meio ambiente vêm se fixando no âmbito dos grandes temas contemporâneos. Busca-se constantemente ressaltar a importância de uma relação positiva e construtiva do homem com o meio ambiente. Sendo assim, é lógica e explicável a preocupação que a sociedade tem de contemplar as questões relacionadas ao meio em que está inserido.

\footnotetext{
"As mudanças sociais, culturais, políticas e econômicas, que se evidenciam nos últimos tempos, provocam um quadro desolador quando ocorre em forma de intervenções bastante negativas para o meio ambiente, natureza. Colocando, desse modo, a sustentabilidade ambiental no ápice das discussões sobre meio ambiente. Isto pressupõe que todos os segmentos da sociedade devem ser envolvidos e que a importância de se estudar o tema "desenvolvimento sustentável", deve-se em grande medida ao fato de que este é um processo longo e contínuo" (MONTEIRO et al., 2019, p. 13).
}

Devido à preocupação com a sustentabilidade e com o aproveitamento dos resíduos de construção e demolição (RCD), estudos sobre o tema têm sido realizados. Na tabela abaixo podemos verificar algumas conclusões desses estudos, extraídas da bibliografia analisada.

Tabela 1 - conclusão de estudos sobre sustentabilidade e aproveitamento de RCD

\begin{tabular}{ll}
\hline \multicolumn{1}{c}{ ESTUDO } & \multicolumn{1}{c}{ CONCLUSÃO } \\
\hline Viana et al. (2013) & Ressalta a importância da gestão integrada de resíduos sólidos para a sustentabilidade. \\
\hline Rodrigues et al. (2014) & A falta de inovação nos sistemas construtivos é um dos motivos de geração de resíduos. \\
\hline Udawatta et al. (2015) & A melhoria na gestão de resíduos na construção depende de aspectos tecnológicos e humanos. \\
& $\begin{array}{l}\text { Uma forma de sustentabilidade na destinação dos resíduos da construção civil é implantar atividades de } \\
\text { reciclagem e reaproveitamento de produtos e embalagens; implantar atividades de educação ambiental; } \\
\text { executar bons controles de entradas, processos mapeados e formalizados; rede logística planejada; re- } \\
\text { lações colaborativas entre clientes e fornecedores; procurar identificar desperdícios ao longo da cadeia } \\
\text { produtiva e trabalhar com a vida útil do produto. }\end{array}$ \\
& O estudo sobre a sustentabilidade em canteiros de obras ainda precisa de um melhor aprofundamento \\
Almeida et al. (2015) & quanto às soluções aplicáveis.
\end{tabular}


Este estudo permitiu identificar a influência que a fase de execução (canteiro de obras) tem sobre o em-

Zeule \& Sheila (2017) preendimento como um todo, avaliando as diversas ocorrências de possibilidade de implantação das boas práticas de sustentabilidade.

\begin{tabular}{ll} 
Marinho et al. (2019) & $\begin{array}{l}\text { Há necessidade de consciência pela responsabilidade socioambiental por parte de todos os segmentos } \\
\text { envolvidos na cadeia produtiva da construção civil. }\end{array}$ \\
& Ao aplicar processos denominados verdes, entre eles a gestão de resíduos da construção civil, tem-se \\
Roque \& Pierre (2019) & $\begin{array}{l}\text { menor pressão do setor sobre os recursos naturais e benefícios como a redução de custos de produção e de } \\
\text { custos operacionais que seriam arcados pelo consumidor final. }\end{array}$ \\
& $\begin{array}{l}\text { Verificaram-se com esta pesquisa diferentes contribuições da reutilização das sobras de piso da construção } \\
\text { Roque } \text { et al. (2020) } \\
\text { civil para a sustentabilidade, em suas dimensões ambiental, social e econômica no município da Estância } \\
\text { Turística de São Roque. }\end{array}$ \\
\hline
\end{tabular}
Fonte: Construção do Autor

\title{
CONTEXTO HISTÓRICO
}

A reciclagem dos resíduos acontece desde a antiguidade, de acordo com Fernandes e Filho (2016, p. 9):

\begin{abstract}
A engenharia na antiguidade costumava trabalhar com a reciclagem dos Resíduos gerados por destruições ou demolições e ainda os que sobravam de processos construtivos, devido, principalmente, a dificuldade de transporte de matérias primas e RCD's, tornando lógica e necessária a reciclagem ou reutilização dos mesmos.
\end{abstract}

As primeiras usinas de reciclagem de resíduos de construção civil no Brasil foram instaladas pelas Prefeituras de São Paulo, SP (1991), Londrina, PR (1993), e Belo Horizonte, MG (1994), ao verem que os benefícios ambientais e econômicos eram positivos. Entre 1999 e 2005 outras prefeituras também implantaram os planos de gerenciamento de RCD, mas só foi homologada com a Resolução CONAMA n. 307, que definiu que as geradoras seriam obrigadas a desenvolver e implantar um plano de gestão de RCD. Essa prática ganhou força e incentivou suas implantações também em canteiros de obras e elaborações de normas técnicas pela ABNT (SANTOS, 2019, p. 10).

\section{CLASSIFICAÇÃO DOS RESÍDUOS}

De acordo com a Resolução Conama n 307/2002, a classificação dos resíduos é definida em quatro classes, sendo elas:

- Classe A - são os resíduos reutilizáveis ou recicláveis como agregados, tais como: a) de construção, demolição, reformas e reparos de pavimentação e de outras obras de infraestrutura, inclusive solos provenientes de terraplanagem; b) de construção, demolição, reformas e reparos de edificações: componentes cerâmicos (tijolos, blocos, telhas, placas de revestimento etc.), argamassa e concreto; c) de processo de fabricação e/ou demolição de peças pré-moldadas em concreto (blocos, tubos, meio-fios etc.) produzidas nos canteiros de obras; - Classe B - são os resíduos recicláveis para outras destinações, tais como plásticos, papel, papelão, metais, vidros, madeiras, embalagens vazias de tintas imobiliárias e gesso; 
- Classe C - são os resíduos para os quais não foram desenvolvidas tecnologias ou aplicações economicamente viáveis que permitam a sua reciclagem ou recuperação;

- Classe D - são resíduos perigosos oriundos do processo de construção, tais como tintas, solventes, óleos e outros ou aqueles contaminados ou prejudiciais à saúde oriundos de demolições, reformas e reparos de clínicas radiológicas, instalações industriais e outros, bem como telhas e demais objetos e materiais que contenham amianto ou outros produtos nocivos à saúde (BRASIL, 2002, p. 572).

Já, segundo a NBR 10004, classificam-se em classe I - resíduos perigosos e classe II - resíduos não perigosos. A classe I são os resíduos que apresentam periculosidade, ou seja, que representam risco à saúde pública e ao meio ambiente. A classe II divide-se em classe II A - não inertes e classe II B - inertes, sendo a classe II A materiais que reagem com a natureza com propriedades de biodegradabilidade, combustibilidade ou solubilidade em água. E a classe II B são materiais que não reagem com a natureza e assim não liberam substâncias que prejudiquem o meio ambiente, tais como: pedras, areias, vidros etc (ABNT, 2004).

\section{RECICLAGEM E REUTILIZAÇÃO DOS RESÍDUOS NA CONSTRUÇÃO CIVIL}

"Segundo Pinto e colaboradores (2005), deve haver atenção especial sobre a possibilidade da reutilização de materiais ou mesmo a viabilidade econômica da reciclagem dos resíduos no canteiro, evitando sua remoção e destinação".

De acordo com a Resolução Conama no 307/2002, reutilização "é o processo de reaplicação de um resíduo, sem transformação do mesmo" e, a reciclagem "é o processo de reaproveitamento de um resíduo, após ter sido submetido à transformação" (BRASIL, 2002, p. 2). O processo de reciclagem vai desde a gestão ambiental no canteiro de obras, com a separação correta e acondicionamento do entulho em caçambas ou baias, até a sua destinação final.

Como visto anteriormente, a Resolução Conama n 307/2002 classifica os resíduos em quatro classes e também define a destinação dos resíduos de cada classe:

I - Classe A: deverão ser reutilizados ou reciclados na forma de agregados ou encaminhados a aterro de resíduos classe A de reservação de material para usos futuros;

II - Classe B: deverão ser reutilizados, reciclados ou encaminhados a áreas de armazenamento temporário, sendo dispostos de modo a permitir a sua utilização ou reciclagem futura; III - Classe C: deverão ser armazenados, transportados e destinados em conformidade com as normas técnicas específicas.

IV - Classe D: deverão ser armazenados, transportados e destinados em conformidade com as normas técnicas específicas (BRASIL, 2002, p. 3).

Os resíduos possuem condições para serem utilizados como material de construção quando corretamente reciclados, porém por serem formados por vários componentes há baixa utilização dos agregados reciclados, como afirma Vieira e Dal Molin: 
Devidamente reciclado, o entulho apresenta propriedades físicas e químicas apropriadas para seu emprego como material de construção. No entanto, os RCC são formados de uma grande variedade de componentes. A proporção desses materiais em diferentes amostras é muito variável e de grande heterogeneidade. Esse é um dos motivos da baixa utilização de agregados reciclados, o que dificulta seu aproveitamento pela indústria (VIEIRA; DAL MOLIN, 2004 apud Evangelista; Costa; Zanta, 2010, p. 27).

“Segundo Vieira e Dal Molin (2004, apud Evangelista; Costa: Zanta, 2010, p. 26), quando se analisa a composição dos resíduos de construção e demolição das cidades, percebe-se que sua composição, em geral, possui elevados percentuais de concreto, material cerâmico e argamassa, independentemente da região, estado e até mesmo país em que foram gerados”.

A reciclagem é possível ser realizada no próprio canteiro de obras, reduzindo o consumo de agregados naturais, os custos de transporte entre outros, conforme afirma Evangelista; Costa; Zanta (2010, p. 27):

A reciclagem, além de ser promovida em instalações permanentes, pode ser realizada no próprio canteiro, utilizando equipamentos móveis. Essa abordagem remete à execução dos processos de britagem e peneiramento no próprio local de produção dos resíduos e de utilização do agregado reciclado logo que é processado. Tal prática reduz o consumo de agregados naturais, a destinação em aterros, os custos de transporte, energia e desgaste com estradas e equipamentos.

Os resíduos de construção e demolição enquadram-se, em geral, na classe A da Resolução 307/2002 do Conama e na classe II-B da NBR 10.004, como destaca Fernandes e Filho (2016, p. 7):

(...) os RCD's enquadram-se, em geral, na Classe A da Resolução 307/2002 do CONAMA e segundo a norma brasileira NBR-10.004 (ABNT, 2004), na classe II-B por serem em sua maioria constituídos de materiais inertes, sendo passíveis de reaproveitamento ou reciclagem desde que não se contaminem com outros materiais como o gesso (classe $\mathrm{C}$ ) ou perigosos como solventes, tintas, amianto e outros (classe D) o que determina o desperdício dos mesmos, e essa segregação desde a geração implica exatamente na mudança de conceitos e envolvimento de todos no canteiro de obras.

“Os resíduos classe A podem ser reutilizados para aterro de terrenos, desde que as orientações da gestão pública sejam obedecidas, ou enviados a recicladores para a produção de agregado reciclado ou ainda armazenados para utilização futura" (CARVALHO, 2008, p. 73).

O tijolo, por exemplo, pode ser reutilizado no canteiro de obra. Os tijolos quebrados durante a construção devem ser britados para que, posteriormente, possam reutilizá-los como base e sub-base de aterros e pavimentos (OLIVEIRA, 2015, p. 19). A argamassa é outro material passível de reciclagem, quando o resíduo puder ser peneirado, resulta então em uma mistura de argamassa e areia, podendo ser reutilizado no processo de fabricação de argamassa de assentamento, argamassa de revestimento e outros, sendo substituídos os agregados naturais (OLIVEIRA, 2015, p. 19).

Já a reciclagem de resíduo de alvenaria, concreto e cerâmica no canteiro de obras deve-se levar em conta a viabilidade econômica, como afirma Pinto: 
A reciclagem de resíduo de alvenaria, concreto e cerâmica no canteiro de obra (reciclagem interna) deve ser feita com base em análise de viabilidade econômica e financeira, considerando aspectos como volume e fluxo estimados de geração; custo com mão-de-obra, equipamento e energia comparado com o do agregado natural e de remoção de RCC; disponibilidade de espaço para armazenamento de estoque; possíveis usos do agregado reciclado; e controle tecnológico do agregado produzido (PINTO, 2005 apud CARVALHO, 2008, p. 73).

Foi realizada uma pesquisa, por Vieira e Dal Molin, para avaliar a viabilidade técnica e econômica do uso de agregados reciclados vindo de resíduos de construção e demolição em concretos, como afirma Evangelista, Costa e Zanta (2010, p. 27):

Vieira e Dal Molin (2004) realizaram pesquisa para avaliar a viabilidade técnica e econômica da utilização de agregados reciclados provenientes de resíduos de construção e demolição em concretos. As autoras realizaram uma comparação entre concretos produzidos com agregados naturais e reciclados com substituições da ordem de $50 \%$ e $100 \%$ de agregados graúdos (AGR) e miúdos (AMR) em cinco composições. Os resultados da pesquisa indicaram que os agregados reciclados em proporções devidamente dosadas podem melhorar algumas propriedades do concreto, como sua resistência a compressão e durabilidade.

Os resíduos de classe $\mathrm{C}$ podem ser depositados em aterros para futura reciclagem e os resíduos da classe D devem ser depositados em aterros de resíduos perigosos:

Os resíduos classe $\mathrm{C}$ podem ser depositados em aterros para futura reciclagem, após desenvolvimento de tecnologia que a viabilize técnica e economicamente. Os classificados como perigosos (D) devem ser depositados, aguardando solução específica e recomenda-se a sua disposição em aterros de resíduos perigosos" (CARVALHO, 2008, p. 73).

Perina e Trannin (2019, p. 4) realizaram um estudo onde foram avaliados os resíduos gerados no canteiro da obra estadual da Companhia de Desenvolvimento Habitacional e Urbano (CDHU), em São Paulo, no período de execução da alvenaria estrutural e revestimentos interno e externo para propor alternativas de aproveitamento para os principais resíduos. Verificou-se que mais da metade dos entulhos pertenciam à classe $\mathrm{A}$ (concreto e blocos, argamassa, solo, areia e pedras) da Resolução 307/2002 do CONAMA, apresentando elevado potencial de reciclagem na forma de agregados. Avaliou-se também os principais componentes dos resíduos, durante a execução da alvenaria predominaram os resíduos de concreto e bloco, juntamente com a madeira utilizada nas formas, na etapa de revestimento houve o predomínio de argamassa, gesso, solo e areia.

Segundo Perina e Trannin (2019, p. 5), os resíduos brutos podem ser aproveitados em obras para aterros. Pode-se, também, utilizar as aparas de blocos para preencher vãos, na execução de vedações em alvenaria. Outra possibilidade é britar os resíduos para empregá-los para enchimentos, estabilização de terrenos, sub-base e base de pavimentos, contrapisos, drenagens, produção de argamassas, e concretos não estruturais, etc. "A produção de agregados reciclados por meio de britagem, peneiramento e balanceamento granulométrico, pode estar relacionada ao processamento 
dos resíduos no próprio canteiro de obras ou em unidades de reciclagem externas" (PERINA; TRANNIN, 2019, p. 5).

O solo pode ser aproveitado para aterros de resíduos de classe A que abrangem a recuperação de áreas degradadas pela atividade de mineração e serviços de regularização topográfica de terrenos e a areia é possível a sua utilização na produção de argamassas no próprio canteiro, como afirmam Perina e Trannin (2019, p. 5):

\begin{abstract}
No caso do solo, os aterros de RCC de classe A abrangem a recuperação de áreas degradadas pela atividade de mineração e serviços de regularização topográfica de terrenos, por meio de obras de engenharia com capacidade de receber resíduos, definidas por projetos específicos. Outra alternativa viável de aproveitamento na forma de agregados reciclados é a utilização da areia na produção de argamassas no próprio canteiro para assentamento de cerâmica e contrapiso.
\end{abstract}

As sobras de gesso deverão ser enviadas para empresas de cargas para destinação dos resíduos em indústrias de cimento e as peças de madeira podem ser reutilizadas exaustivamente e redimensioná-las para outros usos. Esgotadas as possibilidades de reuso na obra, a madeira deverá ter seu destino a unidades que trituram estes resíduos, podendo ser utilizados como combustível em fornos e caldeiras substituindo a madeira virgem (PERINA; TRANNIN, 2019, p. 5).

Como expõe Oliveira (2015, p. 18), a madeira tem diversas formas de utilização:

A madeira pode ser utilizada de diversas formas na construção, podendo fazer parte da própria edificação (janelas, portas), como também ser utilizada como material de apoio (pallets, formas para estruturas). Em obras de nova construção, as madeiras com possibilidades de reutilização são aquelas usadas como material de apoio.

Foi realizada uma pesquisa para a utilização de entulho para a produção de argamassas, na qual foram distribuídas 33 amostras pelos depósitos dos resíduos na cidade de São Carlos (SP). Os resíduos foram separados em cinco categorias, de acordo com as suas características granulométricas. Posteriormente, analisou-se o comportamento desses resíduos como agregado na produção de argamassas, comparando-o ao uso do agregado natural. Obteve-se bons resultados na resistência à compressão das argamassas com a presença de cal, atribuindo esse resultado a dois fatores: à reação pozolânica (reação entre a adição mineral e a cal) dos finos reativos dos resíduos em presença da cal e a maior velocidade de carbonatação (LIMA, 2005, p. 20).

"Todos os envolvidos com o sistema de gerenciamento de resíduos devem ser qualificados e cadastrados pela construtora e todo resíduo retirado do canteiro deve ter sua destinação registrada para sua quantificação e comprovação de adequação" (CARVALHO, 2008, p. 73).

"O futuro dos agregados reciclados será impulsionado pela indisponibilidade de aterros, por uma maior aceitação do produto, pelas políticas governamentais de incentivo ao uso dos agrega- 
dos reciclados, bem como, pelas exigências ambientais e de uma economia sã" (EVANGELISTA; COSTA; ZANTA, 2010, p. 27).

A tabela abaixo apresenta alguns estudos recentes sobre o aproveitamento de RCD, extraídas da bibliografia analisada.

Tabela 2 - conclusão de alguns estudos recentes sobre reaproveitamento de RCD.

\begin{tabular}{|c|c|}
\hline ESTUDO & S̃̃O \\
\hline Bessa et al. (2019) & $\begin{array}{l}\text { Foi comprovada a viabilidade técnica do uso do RCD processado em Belo Horizonte -MG, na cadeia da } \\
\text { construção civil em produção de componentes sustentáveis }\end{array}$ \\
\hline Perina; Trannin (2019) & $\begin{array}{l}\text { Para o aproveitamento dos RCC gerados no canteiro de obras da CDHU, em Pindamonhangaba (SP), no } \\
\text { período de execução da alvenaria estrutural e revestimentos interno e externo foi proposta: a utilização dos } \\
\text { resíduos de blocos e argamassa, em enchimento de degraus de escada e rasgos de paredes para tubulações } \\
\text { hidráulicas e elétricas, entre outros. }\end{array}$ \\
\hline Trannin; Pancieri (2019) & $\begin{array}{l}\text { O uso de agregados reciclados em pavimentação, em padrões que atendam as normas brasileiras, é uma } \\
\text { excelente estratégia para diminuir os impactos ambientais causados pelos resíduos de construção e demo- } \\
\text { lição e pela extração de recursos naturais não renováveis e deve ser uma prática incentivada e disseminada. }\end{array}$ \\
\hline Santos et al. (2019) & $\begin{array}{l}\text { A adição de RCD nas misturas de solo-cal contribuiu para o aumento do desempenho mecânico e, dessa } \\
\text { forma, a adoção dessas misturas parece ser uma solução interessante para a destinação final dos resíduos } \\
\text { da construção civil. }\end{array}$ \\
\hline Garcia (2019) & $\begin{array}{l}\text { As placas cimentícias, objeto de estudo, produzidas no laboratório, possuem características consideráveis e } \\
\text { seu uso no revestimento de calçadas poderá contribuir de forma econômica e sustentável em Caratinga/MG. }\end{array}$ \\
\hline Silva L. et al. (2019) & $\begin{array}{l}\text { Os resultados dos ensaios permitiram inferir que as características dos concretos foram satisfatórias, uma } \\
\text { vez que, o concreto com a presença dos resíduos obteve valores próximos ao concreto convencional para } \\
\text { todos os ensaios realizados. }\end{array}$ \\
\hline $\begin{array}{l}\text { Bonadiman Buligon } \\
\text { et al. }(2020)\end{array}$ & $\begin{array}{l}\text { Apresentação de resultados satisfatórios da utilização da mistura de solo natural com agregado miúdo } \\
\text { (obtido através reciclagem de resíduos da construção) em bases e sub-bases de pavimentos econômicos. }\end{array}$ \\
\hline Queiroz et al. (2020) & $\begin{array}{l}\text { A partir de programa experimental, observou-se que os agregados oriundos de RCD desempenharam um } \\
\text { bom potencial de utilização em revestimentos asfálticos à quente, baseado nas análises dos corpos de prova. }\end{array}$ \\
\hline San & $\begin{array}{l}\text { Foram analisados traços de contrapiso e de emboço interno e externo, considerando substituição de areia } \\
\text { natural por agregado reciclado nos percentuais de } 25 \% \text { e } 50 \% \text {. } \\
\text { Os agregados naturais e os reciclados apresentaram similaridade quanto à forma e à angularidade, além } \\
\text { das propriedades de granulometria, módulo de finura, massa unitária e massa específica. }\end{array}$ \\
\hline Thamirys et al. (2020) & $\begin{array}{l}\text { Este estudo verificou-se que é justificável a utilização de resíduo de construção civil em camadas de pavi- } \\
\text { mentação, particularmente em revestimento primário e sub-base. }\end{array}$ \\
\hline Nogueira (2020) & $\begin{array}{l}\text { Na cidade de Manaus, sugere-se que, além da elaboração do Plano de Gerenciamento de Resíduos Sólidos, } \\
\text { o poder público e a iniciativa privada repensem um modelo estrutural e aplicável que atenda a construção } \\
\text { civil, a fim de que o reaproveitamento dos materiais em projetos de construção civil esteja atrelado aos } \\
\text { princípios da sustentabilidade. }\end{array}$ \\
\hline
\end{tabular}

Fonte: Construção do Autor

\section{CONSIDERAÇÕES FINAIS}

Diante de todas as informações abrangidas neste trabalho, por meio das referências apresentadas, é visível ainda a falta de manejo de resíduos de construção e demolição por parte dos construtores. A geração de resíduos é preocupante em decorrência do crescimento imobiliário gradativo, provocando impactos ambientais significativos. 
Os entulhos, que são constituídos na maioria de resíduos de classe A, de acordo com a Resolução 307/2002 do CONAMA, podem e devem ser reciclados ou reutilizados, com o intuito de diminuir os impactos ambientais causados pelo seu descarte indevido.

Portanto, a reutilização e reciclagem dos resíduos de construção e demolição pode substituir de maneira satisfatória os recursos naturais, preservando-os e prolongando o tempo de vida útil dos mesmos, diminuindo os impactos causados ao meio ambiente e garantindo uma boa qualidade de vida para as futuras gerações. Ademais, fica nítida a importância do manejo dos resíduos dentro do canteiro de obras, desde a geração até sua destinação, facilitando a identificação de materiais reutilizáveis.

O estudo sobre o tema ainda pode ser melhor explanado e continuado em trabalhos futuros quanto a aplicação e frequência da gestão e uso dos resíduos nos canteiros de obra das empresas. Este artigo oferece uma contribuição para as empresas de construção civil, que desejam investir em sustentabilidade.

Dentro dos estudos analisados na revisão bibliográfica, verifica-se a realização de diversas ações para o aproveitamento de RCD. O aproveitamento dos resíduos da construção civil pode atender aos Objetivos de Desenvolvimento Sustentável das Nações Unidas, em especial o Objetivo 12. Esse objetivo direcionará as empresas de construção para desenvolver o projeto, pensando na reciclagem e reutilização no canteiro de obras, ajudando na conservação do meio ambiente.

\section{REFERÊNCIAS}

ALBUQUERQUE, Thálya Lacerda; SANTANA, Dr. Claudemir G. Desperdício de material no canteiro de obras de médio porte em São Luís- MA na atualidade. Revista do Centro de Estudos em Desenvolvimento Sustentável, no 9. Disponível em: https://bit.ly/2Zc9wbK. Acesso em: 22 jun. 2020.

ALMEIDA, Lavocat Galvão de Almeida; PICCHI, Flavio. Sustentabilidade em Canteiro de Obras. XXXVI Encontro Nacional de Engenharia de Produção (ENEGEP) - Contribuições da Engenharia de Produção para Melhores Práticas de Gestão e Modernização do Brasil. João Pessoa. 2016.

AUTOSSUSTENTÁVEL. Sustentabilidade ao alcance de todos. Disponível em: https://bit.ly/ 3vvH1Sc. Acesso em: out. 2020.

ASSOCIAÇÃO BRASILEIRA DE NORMAS TÉCNICAS. NBR 10004. Resíduos sólidos: classificação. Rio de Janeiro, 2004. 
BESSA, Sofia; MELLO, Tiago; BELO, Barbara; MIRANDA, Mariana; OSÓRIO, Roberto; BEZERRA, Augusto. Comportamento mecânico de alvenarias de terra com resíduos de construção e demolição. Mix Sustentável, v. 5, n. 4, p. 53-62. Florianópolis. Disponível em: 10.29183/2447-3073.MIX2019. v5.n4.53-62. 2019.

BLumenschein, R. N. Gestão de Resíduos Sólidos em Canteiros de Obras. Brasília, DF: Centro de Apoio ao Desenvolvimento Tecnológico, Universidade de Brasília, 2007. Dossiê Técnico.

BONADIMAN BULIGON, Liliane; FERNANDES, Selton de Sousa Lima; AZOLIM, Joceane. Resíduos de construção civil: uso em pavimentos econômicos a partir de misturas com solo argiloso. $1^{\circ}$ Congresso Sul Americano de Resíduos Sólidos e Sustentabilidade. Gramado - RS, 2020.

BRASIL. Ministério do Meio Ambiente. Resolução Conama n 307, de 5 de julho de 2002. Estabelece diretrizes, critérios e procedimentos para a gestão dos resíduos da construção civil. Diário Oficial da União, Brasília, 17 jul. 2002.

CARVALHO, Patrícia Menezes. Gerenciamento de resíduos de construção civil e sustentabilidade em canteiros de obras de Aracaju. Dissertação de Mestrado. Núcleo de Pós-Graduação em Desenvolvimento e Meio Ambiente, Universidade Federal de Sergipe. São Cristóvão, 2008. Disponível em: https://bit.ly/2Z8MkLX. Acesso em: 23 jun. 2020.

COSTA, Nébel da; JUNIOR, Newton da Costa; LUNA, Mônica; SELIG, Paulo; ROCHA Janaíde. Planejamento de programas de reciclagem de resíduos de construção e demolição no Brasil: uma análise multivariada. Scielo. Rio de Janeiro, 2006. Disponível em: https://bit.ly/2XwPtnJ. Acesso em: 24 jun. 2020.

ESSOLAR. Conheça os 7 R's da Sustentabilidade e repense seus hábitos. 2018. Disponível em: https://bit.ly/3B2KJ72. Acesso em: 02 out. 2020.

EVANGELISTA, Patricia Pereira de Abreu; COSTA, Dayana Bastos; ZANTA, Viviana Maria. Alternativa sustentável para destinação de resíduos de construção classe A: sistemática para reciclagem em canteiros de obras. Ambiente Construído, v. 10, n. 3. Porto Alegre, 2010. Disponível em: https://bit.ly/3C2QC1T. Acesso em: 24 jun. 2020. 
FERNANDES, Maria da Paz Medeiros; FILHO, Luiz Carlos Pinto da Silva. Gestão de resíduos: construção e desconstrução de conceitos no canteiro de obras. XIII Encontro Nacional de Tecnologia do Ambiente Construído. Canela, 2016.

GARCIA, Hiury George. $O$ uso da reciclagem de resíduos gerados pela construção civil: proposta de renovação das calçadas de Caratinga-MG, utilizando placas cimentícias produzidas com agregado reciclado. Monografia apresentada ao Curso de Arquitetura e Urbanismo da Faculdade Doctum de Caratinga. Caratinga, 2019.

IDEC - INSTITUTO BRASILEIRO DE DEFESA DO CONSUMIDOR. Conheça e pratique os 7 Rs do consumo sustentável. 2019. Disponível em: https://bit.ly/2Za1r7a. Acesso em: 02 out. 2020.

LIMA, Francisco Sales Neves de Souza. Aproveitamento de resíduos de construção na fabricação de argamassas. 2020. Dissertação (Mestrado. Programa de Pós-Graduação em Engenharia Urbana) - Universidade Federal da Paraíba. João Pessoa, 2005. Disponível em: https://bit.ly/3ne7y2S. Acesso em: 28 jun. 2020.

MARINHO, Jefferson Luiz Alves. Tratamento de resíduos da construção civil: Parcerias e políticas públicas visando a sustentabilidade. Meio Ambiente em Foco - Volume 9, capítulo 04. Belo Horizonte - MG: Poisson, 2019.

MONTEIRO, Vicente da Silva; GOIS, William Novais; TENÓRIO, Adirlene Pontes de Oliveira; BARBOSA, Romero Henrique de Almeida; SANTA RITA; Ana Elisabeth Cavalcante. Desenvolvimento Sustentável no Brasil. Meio Ambiente em Foco - Volume 9, Capítulo 02. Belo Horizonte - MG: Poisson, 2019.

OLIVEIRA, Bárbara Tannus de. Uso de resíduos de Construção e Demolição em Argamassas para revestimento de alvenaria. Projeto de Graduação. Escola Politécnica - departamento de construção civil, Universidade Federal do Rio de Janeiro. Rio de Janeiro, 2015. Disponível em: https://bit.ly/ 3vvJnAC. Acesso em: 28 jun. 2020.

ONU - ORGANIZAÇÃO DAS NAÇÕES UNIDAS. Objetivo de Desenvolvimento Sustentável 12: Consumo e produção responsáveis. Brasília, 2020. Disponível em: https://bit.ly/3m1JBfP. Acesso em: 02 out. 2020. 
ONU - ORGANIZAÇÃO DAS NAÇÕES UNIDAS. Os Objetivos de Desenvolvimento Sustentável no Brasil. Brasília, 2020. Disponível em: https: https://brasil.un.org/pt-br/sdgs. Acesso em: 02 out. 2020.

PERINA, Júlia Monfredini; TRANNIN, Isabel Cristina de Barros. Proposta para aproveitamento de resíduos da construção civil gerados em canteiros de obras. XL International Sodebras Congress. Volume 14, nº 59. Vitória. 2019.

PERSEGONA, Eros Daksa Perdigão. Sustentabilidade na destinação de resíduos da Construção Civil. Monografia. Especialização em Gestão Ambiental em Municípios, Universidade Tecnológica Federal do Paraná. Medianeira, 2015.

PINTO, Tarcísio de Paula; GONZÁLEZ, Juan Luís Rodrigo. Manejo e gestão de resíduos da construção civil. Brasília: Caixa, Volume 1, 2005. Disponível em: https://bit.ly/3ncPsOJ. Acesso em: 26 jun. 2020.

QUEIROZ NETO, M. L., AMORIM, E. F., FRANÇA, F. A. N. ; MEDEIROS, M. K. S. Avaliação de um trecho experimental de pavimentação urbana em concreto asfáltico à quente com resíduos de construção e demolição de obras (RCD) como camada de revestimento. 2020. Rev. Gest. Ambient. e Sust. - GeAS, 9(1), 1-18. Disponível em. https://doi.org/10.5585/geas.v9i1.16108. Acesso em: nov. 2020.

RODRIGUES, C. et al. Análise da gestão e aplicação de projeto de gerenciamento de resíduos da construção civil. In: XV ENTAC. Anais... Maceió: ANTAC, 2014.

ROQUE, Luiz Carlos; SOUZA, Vanessa Aparecida Feijó; TOLEDO, Renata Ferraz. Reutilização de sobras de piso da construção civil na perspectiva da sustentabilidade. Revista Gestão \& Sustentabilidade Ambiental, Florianópolis, v. 9, n. 4, p. 739-760, dez. 2020.

ROQUE, Rodrigo Alexander Lombardi; PIERRI, Alexandre Coan. Intelligent use of natural resources and sustainability in civil construction. Research, Society and Development, [S. 1.], v. 8, n. 2 , p. e3482703, 2019. DOI: 10.33448/rsd-v8i2.703. Disponível em: https://bit.ly/3G5VOrL. Acesso em: out. 2020 .

SANTOS, D. V. ; CABRAL, A. E. B. Análise técnica da reciclagem de resíduos de construção em canteiro de obras. Ambiente Construído, Porto Alegre, v. 20, n. 3, p. 363-383, 2020. 
SANTOS, Fernando; LUKIANTCHUKI, Juliana; ILDEFONSO, Jesner Sereni; CORDEIRO, Jeselay dos Reis. Avaliação do módulo de resiliência de misturas de solo, cal e resíduo de construção e demolição (RCD). $15^{\circ}$ Congresso Brasileiro de Geologia de Engenharia e Ambiental. 2019.

SILVA, L. R. da; GAMA, K. N. de C.; SALLES, P. V. ; BRAGA, F. C. S. Concrete with rice husk ash and construction and demolition wastes. Research, Society and Development. 2019. v. 8, n. 4. Disponível em: https://rsdjournal.org/index.php/rsd/article/view/861. Accesso em: out. 2020.

TELLO, Rafael; RIBEIRO, Fabiana Batista. Guia CBIC de boas práticas em sustentabilidade na indústria da Construção. Brasília: Câmara Brasileira da Indústria da Construção; Serviço Social da Indústria; Nova Lima: Fundação Dom Cabral, 2012.

THAMIRYS, Suelle da Silva; MARQUES, Mirella Maria Nóbrega; ELDEIR, Soraya Giovanetti. Desmaterialização dos resíduos sólidos: estratégias para a sustentabilidade. Recife: EDUFRPE: Gampe, 1 livro digital (587 p.). 2020.

TRANNIN, Isabel; PANCIERI, Tarcísio. (2019). Uso de agregados reciclados de resíduos da construção e demolição como alternativa sustentável para a pavimentação. Revista SODEBRAS, v. 14 , p. 26-31. 2019.

UDAWATTA, N. et al. Improving waste management in construction projects: An Australian study. Resources, Conservation and Recycling, v. 101, p. 73-83, 2015.

VIANA, E. T. et al. Implementation of environmental management on a construction site. Applied Mechanics and Materials. p. 441-444. 2013. Disponível em: https://bit.ly/3E5TNKa. Acesso em: out. 2020

VIEIRA, Geilma Lima; DAL MOLIN, Denise Carpena Coutinho. Viabilidade Técnica da Utilização de Concretos com Agregados Reciclados de Resíduos de Construção e Demolição. Ambiente Construído, Porto Alegre, v. 4, n. 4, p. 47-63, dez. 2004.

ZEULE, Ludimilla; SERRA, Sheyla. (2017). Boas Práticas de Sustentabilidade em Canteiros de Obras. 2017. Disponível em: https://bit.ly/3vxXg17. Acesso em out. 2020.

CARVALHO, Patrícia Menezes. Gerenciamento de resíduos de construção civil e sustentabilidade em canteiros de obras de Aracaju. Dissertação de Mestrado. Núcleo de Pós-Graduação em Desenvolvimento e Meio Ambiente, Universidade Federal de Sergipe. São Cristóvão, 2008. Disponível em: https://bit.ly/2XwQxrJ. Acesso em: 23 jun. 2020. 